\title{
ESTIMATION OF WATER PRODUCTIVITY AND CALIBRATION AND VALIDATION OF THE CROPSYST MODEL FOR RICE UNDER NITROGEN AND IRRIGATION MANAGEMENT
}

\author{
MIRAKHORI, M. ${ }^{1}-$ MiRSHEKARI, B. ${ }^{1 *}-$ AMIRI, E. $^{2}-$ PAKNEJAD, F. $^{3}-$ YARNIA, M. $^{1}$ \\ ${ }^{I}$ Department of Agronomy and Plant Breeding, Tabriz Branch, Islamic Azad University \\ Tabriz, Iran \\ (e-mail:Mojtaba.mirakhori@yahoo.com; m.yarnia@yahoo.com) \\ ${ }^{2}$ Department of Agronomy, Islamic Azad University, Lahijan Branch, Lahijan, Iran \\ (e-mail: eamiri57@yahoo.com) \\ ${ }^{3}$ Department of Agronomy and Plant Breeding, Karaj Branch, Islamic Azad University \\ Karaj, Iran \\ (e-mail: farzadpaknejad@yahoo.com) \\ *Corresponding author \\ Mirshekari@iaut.ac.ir; phone: +98-914-316-8208 \\ (Received $18^{\text {th }}$ Nov 2017; accepted $26^{\text {th }}$ Mar 2018)
}

\begin{abstract}
Simulation of yield response to water and fertilizer plays a key role in improving the efficiency of agricultural water. In this regard, the purpose of this study is the calibrating and validating of the CropSyst model to evaluate the effect of nitrogen fertilization and irrigation on the growth of rice in the crop field at the Rasht Rice Research Institute between 2013 and 2014. Three irrigation treatments (continuous, around five and eight days) were considered as the main factors and the amount of nitrogen in four concentration $\left(0,90,120\right.$, and $\left.150 \mathrm{~kg} \mathrm{~N} \mathrm{ha}^{-1}\right)$ as a sub-factor. Based on the evaluation results it can be concluded that the CropSyst model, with the normalized root mean squared error (RMSE $\left.{ }_{n}\right) 7$ and $15 \%$ with explanation factor, $\mathrm{R}^{2}$ of $0.73-0.84$ for simulating the rice grain yield, and also $\mathrm{RMSE}_{\mathrm{n}} 9$ and $10 \%$, $\mathrm{R}^{2}$ of $0.77-0.82$ for simulating the biological yield, had the appropriate accuracy of the simulations. According to $\mathrm{RMSE}_{\mathrm{n}} 1$ and $0.8 \%, \mathrm{R}^{2}$ of $0.58-0.73$ for simulating the leaf area index, suggested a moderate simulation. These results showed that a reasonable estimate of the model as the efficiency of a model for the grain yield, biological yield, and LAI were $0.87,0.98$, and 0.80 , respectively. The results of the simulation based on the amount of transpiration water productivity for both years showed that treatment $\mathrm{I}_{3} \mathrm{~N}_{2}$ and $\mathrm{I}_{3} \mathrm{~N}_{3}$ had the highest amount. The amount of evaporation in irrigation water management two-year period only $39 \%$ of evapotranspiration is evaporated, While the amount of intermittent irrigation management 5 and 8 days, respectively, 35\% and 32\% respectively. These subjects simulations suggest that, given the good models and maximum data consistency, if management is aimed at maximizing the efficiency of water use can solve these models as a means to support the planning application.
\end{abstract}

Keywords: intermittent irrigation, nitrogen, modeling, simulation

\section{Introduction}

Water consumption improvement in agriculture is very important, compared with other sectors, because of the existing complexity in production, and the exploitation process and optimized application of irrigation water and nitrogen, especially in dry and semi-dry areas facing water constraints, is an important goal in this field (Raza et al., 2014). Climate changes, degrading of water resources and continuous drought has influenced agriculture in general and farmers' incomes specifically (Rezaei et al., 2013). As rice receives more irrigation water than other grain crops, developing water-saving 
irrigation approaches for rice re seen as a key component to deal with water shortages (Li and Barker, 2004). In recent years, many efforts have been applied in Iranian rice farms to decrease water consumption, and numerous reports have been published about the effect of low irrigation in decreasing water consumption and increasing rice efficiency (Pirmoradian et al., 2004; Razavipour and Kavosi, 2007). According to these reports, by changing the irrigation method from flood to intermittent irrigation without decreasing yield, or with an acceptable percent in decline, we can economize the use of water and increase the efficiency (Asadi et al., 2003). One of the most important zones of rice production in Iran is Guilan Province. Currently, climate change, reduction of fresh water, inappropriate use of water resources, construction of several dams across the White River basin, and the drought in the agricultural sector have threatened rice production and the income of farmers in the region (Zare et al., 2014)

These reports showed that permanent flood irrigation is not only a necessity but, also in dry and semi-dry areas in which the higher efficiency is important, we need to accept the expense of management to decrease the time and amount of irrigation (Razavipour and Kavosi, 2007). Additionally, in some cases, the average water pressure was recommended for better yield (Asadi et al., 2003). In some physiological periods of rice, intermittent pressure, as compared with permanent flood irrigation, caused an increase in the yield, although increasing the pressure will result in a decreased yield (Asadi et al., 2003).

Due to different intervals of time and place, it is difficult to determine various levels of yield through farm experiments. As such, computer simulation models can be used as appropriate tools for cultivation system studies and prepare optimized consumption patterns for the two inputs. Using simulation models is a way to predict and check water balance, growth process simulation, and the study of different management scenarios (Amiri and Rezaei, 2013a). One of the effective methods to reach these goals is the use of some models for plant growth, such as CropSyst (Crop Simulation System), which is a simulation model for rice growth that enables us to obtain the correct results through calculations of data statistics regarding the situation of water, weather, Earth, management system, and plant genetics (Amiri and Rezaei, 2013b). By using this model and its results, we can prevent excess consumption of water and nitrogen fertilizers.

Improvement of the CropSyst model was started by Stokel and colleagues in 1994. CropSyst had been developed during the last 15 years to a multi-crop, multi-year simulation model and can be connected to GIS software, which consist of programs like the CropSyst cultivation simulator system, reconstruction of meteorological data (ClimGen), GIS connection program (ArcCs), watershed models, and several other useful programs (Singh, 2008). This model has been used in various cases and in different areas (Saadati et al., 2012). In Southeast Australia, the CropSyst model could simulate the phenology, dry material, and the yield of wheat, green pea, and mustard (Diaz-Ambrona et al., 2001). Quite well. Since the 1980s, crop modellers have been pointing their attention on rice productions. Part of the APSIM crop models (Confalonieri et al., 2009), and the models of the CERES family basically implement a RUE based approach. Part of the models include crop growth equations based on the transpiration use efficiency (Keating et al., 2003). WARM (Confalonieri et al., 2006) is a novel model for paddy rice simulations developed by an interdisciplinary network of scientists working in different fields of rice research and modelling. The simplified model (CropSyst) may cost less in parameterization terms than the more complex models to achieve a similar level of confidence in the results, but WARM proved more 
accurate than the simplified model. The complexity of WOFOST is required to test hypotheses about processes at a lower level (Confalonieri et al., 2006). Therefore, models that are relatively simple to use with minimal input data that is readily available or easy to obtain may be a more useful analytical tool for technical staff, water managers, policy makers and other end-users in less developed countries (Khov et al., 2017).

Regarding the importance of rice cultivation in Guilan Province, and the necessity to optimize economic use of agriculture inputs, and the need to use simulation models of plant growth in irrigation management, this experiment has been conducted with the aim of gaining the best management for irrigation, nitrogen, and evaluate the application of the CropSyst model for rice yield under various water and nitrogen management scenarios.

\section{Materials and methods}

\section{Field experiments}

A two-year field experiment was conducted at the experimental farm of the Iranian Rice Research Institute in Rasht $\left(37^{\prime} 12^{\circ} \mathrm{N} ; 4^{\prime} 38^{\circ} \mathrm{S} ; 7 \mathrm{~m}\right.$ below sea level) from 2013-2014. The experimental design was a split plot with a complete randomized block and three replicates. The plot size for the subplots was $15 \mathrm{~m}^{2}(3 \mathrm{~m} \times 5 \mathrm{~m})$. In this experiment, the main plots were three irrigation regimes: pond during growth period as a control treatment (I1), 5-day intervals (I2), and 8-day intervals (I3), and subplot treatments of four levels of $\mathrm{N}$ (no $\mathrm{N}$ application (N1), $90 \mathrm{~kg}(\mathrm{~N} 2), 120 \mathrm{~kg}(\mathrm{~N} 3)$, and $150 \mathrm{~kg}(\mathrm{~N} 4)$ ); urea was the source of $\mathrm{N}$. A mixed commercial fertilizer was applied at the rate of $25 \mathrm{~kg} \mathrm{ha}^{-1}$ of phosphorus (P) (in the form of phosphorus pentoxide $\left(\mathrm{P}_{2} \mathrm{O}_{5}\right)$ ) and $75 \mathrm{~kg} \mathrm{ha}^{-1}$ of potassium (K) (in the form of dipotassium oxide $\left(\mathrm{K}_{2} \mathrm{O}\right)$ ). The rice variety 'spring' resulted in the highest yield in Guilan Province. Field experiments (Table 1) were carried out on a clay soil tissue ( $9 \%$ sand, $44 \%$ silt, and $47 \%$ clay). For determining the soil characteristics site of this experiment, several random samples of soil were obtained from a depth of $0-30 \mathrm{~cm}$ before transplanting and adding fertilizers and, after mixing soil samples, soil was sent to the laboratory for analyzing the soil in terms of physical and chemical properties (the results are shown in Table 1). Nitrogen fertilizer was applied three times during bolting, $50 \%$ at the time of transplanting to the field, $25 \%$ at maximum tillering, and $25 \%$ of the land. Irrigation was applied 20 days after transplanting management and to measure how many water counters in each plot were used.

Daily weather data on maximum and minimum temperatures, rainfall, and sunshine hours were collected for the entire growing season from a meteorological station beside the Iranian Rice Research Institute (Fig. 1).

Table 1. Characteristics of the used soil

\begin{tabular}{c|c|c|c|c|c|c|c}
\hline $\mathbf{p H}$ of dough & $\begin{array}{c}\text { Total N } \\
(\mathbf{\%})\end{array}$ & $\begin{array}{c}\mathbf{O C} \\
\mathbf{( \% )}\end{array}$ & $\begin{array}{c}\mathbf{P} \\
(\mathbf{p p m})\end{array}$ & $\begin{array}{c}\mathbf{K} \\
(\mathbf{p p m})\end{array}$ & $\begin{array}{c}\mathbf{C E C} \\
(\mathbf{m e q} / \mathbf{1 0 0} \mathbf{g})\end{array}$ & Tissue & $\begin{array}{c}\text { Depth soil } \\
(\mathbf{c m})\end{array}$ \\
\hline 7.2 & 0.13 & 1.32 & 11.9 & 188 & 31 & Clay & $30-0$ \\
\hline
\end{tabular}




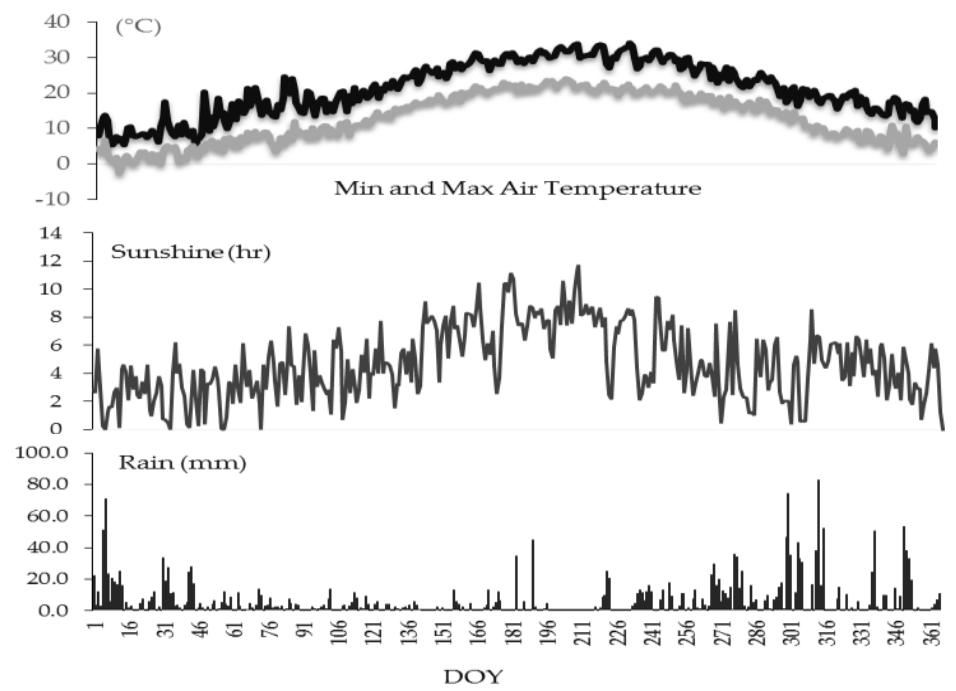

a

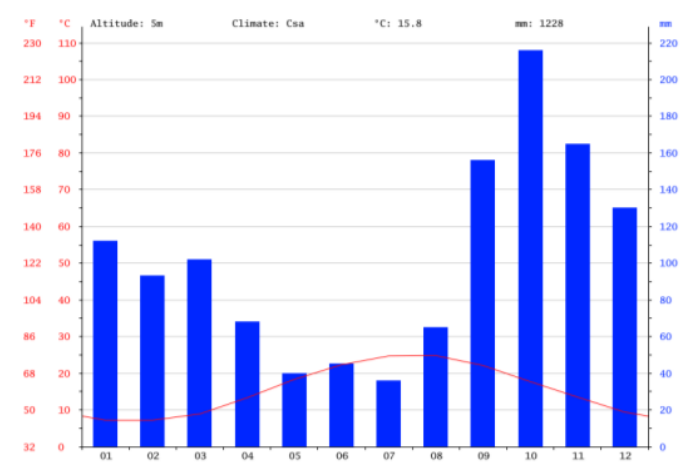

b

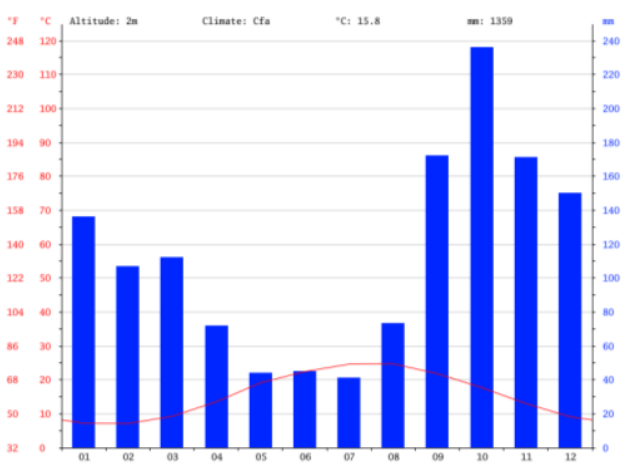

c

Figure 1. a: Measured daily meteorological variables at the study site for the two years of the experiment (from 1 January 2013-22 September 2014). DOY is day of year. b, c: Measured daily Temperature and rainfall at the study site for the two years of the experiment $(2013,2014)$

The continuous irrigation amount during the growing season was about $5 \mathrm{~cm}$. Samples of each plot have been studied with respect to the growth using a destructive analysis method. Plant harvesting was on 11-15 August in all years of the experiment. All plots were bonded and separated by 0.5 -m-wide strips of bare soil to avoid lateral movement of water and nutrients among treatments. The plots were hydrologically separated by plastic sheets installed $40 \mathrm{~cm}$ below the soil surface to restrict water and $\mathrm{N}$ flow between adjacent plots. Measurements of samples were collected at the beginning of transplanting in all treatments, Crop samples were taken at regular intervals of 1015 days to determine leaf area index (LAI) and total and panicle biomass over two years. The LAI of plants was measured by a Model GA-5 manufactured by OSK Japan meter. In other to evaluation of biological yield, $1 \mathrm{~m}^{2}$ of each plot were harvested (Includes all vegetative and reproductive organs of plants top of the soil) and then placing it in the oven until (Drying machine plant material) dried.

\section{CropSyst model descriptions}

Version 3 of the CropSyst model was used in this study. Crop development was simulated on the basis of the accumulated thermal time required to reach each 
phenological stage. In order to evaluate the simulation effects of nitrogen fertilizer and irrigation on the growth yield of rice, some models were used which simulate the plant growth on a day-by-day and phase-by-phase basis to obtain the results. To run the models four sets of data were required as input. File locations, soil, and plant management definition, application, and all required parameters of the model range were stated in the manual model (Stöckle, 2003). Model inputs for the simulation consisted of daily weather information (including maximum and minimum temperature, precipitation, and solar radiation), soil (including physical and chemical properties of each layer), the cultivar characteristics (such as growth factors, growth, yield, and biomass) and crop management practices (including the use of irrigation and fertilizer), and the culture system (Amiri and Rezaei, 2013b).

\section{Simulation model}

Yield simulation of the CropSyst model depended on the total biomass, which accumulated at physiological maturity $\left(B_{\mathrm{PM}}\right)$, and the harvest index $(\mathrm{HI}=$ harvestable yield/aboveground biomass; Eq. 1):

$$
Y=B_{\mathrm{PM}} \mathrm{HI}
$$

Where $\mathrm{Y}$ is yield $\left(\mathrm{kg} \mathrm{m}^{-2}\right)$ and $B_{\mathrm{PM}}$ is also in $\mathrm{kg} \mathrm{m}^{-2}$.

To introduce the processes of the CropSyst simulation, some equations are more important in this study, so they are presented here. Crop transpiration is dependent on biomass production $\left(B_{\mathrm{Pt}}\right)$ and LAI were effective in the output of CropSyst based on calibration results. The third equation is the yield, which was one of the main evaluated outputs. Therefore, these three equations are presented in this paper; also, more information can be found in another study (Stöckle et al., 2003). There is a relationship between crop transpiration and biomass production, which is based on carbon and vapor exchange in leaves. Thus, the potential daily biomass production can be calculated as (Eq. 2; Kumar et al., 2006):

$$
A G B_{P T}=\frac{k_{B T} T_{P}}{V P D}
$$

Where $\mathrm{AG} B_{\mathrm{PT}}$ is the crop transpiration-dependent biomass production $\left(\mathrm{kg} \mathrm{m}^{-2} \mathrm{day}^{-1}\right), T_{P}$ is the crop potential transpiration $\left(\mathrm{kg} \mathrm{m}^{-2} \mathrm{day}^{-1}\right)$, VPD is Average daily steam pressure loss (kPa), and $K_{B T}$ is a biomass-transpiration ratio (kPa).

\section{Water productivity estimation}

In this study, the amount of water productivity was calculated (Eq. 3) based on the sum of water and rainfall, with respect to the amount of water productivity $\mathrm{WP}_{\mathrm{I}+\mathrm{R}}$ $\left(\mathrm{kg} / \mathrm{m}^{2}\right)$, where $\mathrm{Y}$ is the yield $(\mathrm{kg} / \mathrm{h}), \mathrm{I}$ is the amount of irrigation $(\mathrm{mm})$, and $\mathrm{R}$ is the precipitation $(\mathrm{mm})$. The amount of rainfall, evaporation, average maximum daily temperature, and irrigation in the years studied is shown in Table 2.

$$
W P=\frac{Y}{I+R}
$$




$$
-2282-
$$

Table 2. Amounts of water irrigation, precipitation, and evaporation and maximum temperature

\begin{tabular}{c|c|c|c|c|c}
\hline \multicolumn{2}{c|}{2014} & \multicolumn{2}{c|}{$\mathbf{2 0 1 3}$} & \multicolumn{2}{c}{ Treatments } \\
\hline $\mathbf{P}$ & I & P & I & Nitrogen & Irrigation \\
\hline \multirow{5}{*}{59} & 804 & & 744 & $N_{1}$ & \\
& 801 & & 724 & $N_{2}$ & $I_{1}$ \\
& 789 & & 712 & $N_{3}$ & \\
& 759 & & 732 & $N_{4}$ & \\
& 726 & & 701 & $N_{I}$ & \\
& 741 & \multirow{4}{*}{79} & 703 & $N_{2}$ & $I_{2}$ \\
& 746 & & 701 & $N_{3}$ & \\
& 746 & & 707 & $N_{4}$ & \\
& 419 & & 469 & $N_{1}$ & \\
& 459 & & 459 & $N_{2}$ & $I_{3}$ \\
& 496 & & 461 & $N_{3}$ & \\
\hline
\end{tabular}

\section{Calibration of the models}

Initially, soil, weather, and irrigation files were prepared similarly for all models. Then measured and estimated crop parameters were inserted in the models. After calibration of the model and determination of the optimal coefficients, a validation model was performed by using the second year of treatment (Table 3). In these models, plant development was measured with respect to temperature time $\left({ }^{\circ} \mathrm{C}\right.$-days $)$. From the start to the increase in the planting stage, temperature time must be specified for each phenological stage. Based on the type of plant phenology, the important and fundamental steps included the emergence, flowering, time of maximum leaf area index, end of flowering, start of grain filling, and physiological maturity.

Table 3. Some relevant crop parameters used in the CropSyst model for the rice simulation

\begin{tabular}{c|c|c}
\hline Parameters & Amount & Unit \\
\hline Optimum temperature $\left(\mathrm{T}_{\text {opt }}\right)$ & 27 & ${ }^{\circ} \mathrm{C}$ \\
Maximum water uptake & 10 & $\mathrm{~mm}^{-1}$ \\
Maximum rooting depth & 1.5 & $\mathrm{~m}$ \\
Maximum expected leaf area index (LAI) & 5.9 & $\mathrm{~m}^{2} \mathrm{~m}^{-2}$ \\
Specific leaf area (SLA) & 30 & $\mathrm{~m}^{2} \mathrm{~kg}^{-1}$ \\
Leaf duration & 750 & ${ }^{\circ} \mathrm{C}$-days \\
Extinction coefficient for solar radiation (k) & 0.5 & - \\
Emergence Stage & 135 & ${ }^{\circ} \mathrm{C}$-days \\
Peak LAI & 1350 & ${ }^{\circ} \mathrm{C}$-days \\
Begin flowering & 1290 & ${ }^{\circ} \mathrm{C}$-days \\
Begin grain filling & 1300 & ${ }^{\circ} \mathrm{C}$-days \\
Physiological maturity & 1900 & ${ }^{\circ} \mathrm{C}$-days \\
Base temperature $\left(\mathrm{T}_{\text {base }}\right)$ & 12 & ${ }^{\circ} \mathrm{C}$ \\
\hline
\end{tabular}




\section{Model evaluation}

Several statistical methods were used to compare the simulated and observed results. In this article, we used a combination of graphical analyses and statistical measures to compare the simulated and measured final biomass and yield and LAI graphically. In this article, we evaluated model performance by using the absolute root mean square error (RMSE), normalized root mean square error $\left(\mathrm{RMSE}_{\mathrm{n}}\right)$, coefficient of residual mass $(\mathrm{CRM})$, coefficient of determination $\left(\mathrm{R}^{2}\right)$, and effective modeling (EF). RMSE, RMSE ${ }_{n}$, $\mathrm{CRM}$, and $\mathrm{R}^{2}$, index of agreement (IOA), and EF characteristics are common tools to test the goodness of fit of simulation models (Eqs. 4-9; Pala et al., 1996; Fila et al., 2003):

$$
\begin{gathered}
R M S E=\left[\frac{\sum_{i-1}^{n}\left(P_{i}-O_{i}\right)^{2}}{n}\right]^{1 / 2} \\
R M S E n=\frac{R M S E}{\bar{O}} \\
R 2=\frac{\sum_{i-1}^{n}\left(P_{i}-O_{i}\right)^{2}}{\sum_{i-1}^{n}\left(O_{i}-\bar{O}\right)^{2}} \\
E F=\frac{\sum_{i-1}^{n}\left(O_{i}-\bar{O}\right)^{2}-\sum_{i-1}^{n}\left(O_{i}-\bar{O}\right)^{2}}{\sum_{i-1}^{n}\left(O_{i}-\bar{O}\right)^{2}} \\
C R M=\frac{\sum_{i-1}^{n} O_{i}-\sum_{i-1}^{n} P_{i}}{\sum_{i-1}^{n} O_{i}} \\
I O A=\frac{\sum_{i-1}^{n}\left(P_{i}-O_{i}\right)^{2}}{\left|\left(P_{i}-\bar{P}\right)\right|+\left|\left(O_{i}-\bar{O}\right)\right|}
\end{gathered}
$$

Where Pi is the simulated value, Oi is the measured value, and $\mathrm{n}$ is the number of measurements. The simulation was considered excellent if the normalized RMSE was less than $10 \%$, was considered good if the normalized RMSE was greater than $10 \%$ and less than 20\%, was considered fair if the normalized RMSE was greater than $20 \%$ and less than $30 \%$, and was considered poor if the normalized RMSE was greater than $30 \%$. The amounts of RMSE and $\mathrm{RMSE}_{\mathrm{n}}$ were at an optimum status if the simulated and observed were the same, and was equal to zero. If the $p$-value $(p(\mathrm{t}))$ from the paired $t$ test was greater than 0.05 , it was concluded that there were no significant differences existing between the measured and simulated values (Eitzinger et al., 2004). The IOA is also used to evaluate the model; it is a descriptive parameter value between zero and one, indicating how weak the model is in predicting results (Eitzinger et al., 2004). 


\section{Results and discussion}

\section{Calibration of the models}

Initially, soil, weather, and irrigation files were prepared similarly for all models. Then, measured and estimated crop parameters were inserted in the models. The crop parameters used in this study are presented in Tables $4-6$ for the models. A revalidation of the model depends upon its successful calibration based on field experimental data, and the accurate estimation of the specific model's coefficients in a given environment (Eitzinger et al., 2004).

\section{Validation and evaluation of the models}

The model validations were based on the comparison between simulated and observed data for all treatments other than those used in the model calibration. Results showed that the average grain yield of RMSE under calibration and validation conditions was 461 and $847 \mathrm{~kg}$ per hectare, respectively. The average RMSE $\mathrm{n}_{\mathrm{n}}$ of grain yield under calibration and validation conditions were $7 \%$ and $15 \%$, respectively. The amounts of the measured grain yield showed a desirable simulation of this parameter in the agriculture season by the model which we could then use in irrigation planning and nitrogen rice fertilizer management (Tables 4 and 6). Araya et al. (2010) who report a deviation range of validation data of -13 to $15.1 \%$ for grain yield.

Table 4. Observed and simulated grain yields and relative error for rice in 2013

\begin{tabular}{|c|c|c|c|c|}
\hline \multicolumn{2}{|c|}{ Treatment } & \multirow{2}{*}{$\begin{array}{c}\text { Relative error } \\
(\%)\end{array}$} & \multirow{2}{*}{$\begin{array}{c}\text { Simulation grain yield } \\
(\mathrm{kg} / \mathbf{h a})\end{array}$} & \multirow{2}{*}{$\begin{array}{c}\text { Observed grain yield } \\
(\mathrm{kg} / \mathrm{ha})\end{array}$} \\
\hline Irrigation & Nitrogen & & & \\
\hline \multirow{4}{*}{$I_{1}$} & $N_{I}$ & 15 & 5053.8 & 4382.5 \\
\hline & $\mathrm{N}_{2}$ & 7 & 6533.6 & 6120.1 \\
\hline & $N_{3}$ & -15 & 6525.6 & 7664 \\
\hline & $N_{4}$ & -2 & 6953.6 & 7093 \\
\hline \multirow{4}{*}{$I_{2}$} & $N_{l}$ & 3 & 5273.3 & 5135 \\
\hline & $N_{2}$ & -1 & 6001 & 6084.4 \\
\hline & $N_{3}$ & 3 & 6825.9 & 6648.2 \\
\hline & $N_{4}$ & 10 & 7163.1 & 6478 \\
\hline \multirow{4}{*}{$I_{3}$} & $N_{l}$ & 9 & 5024 & 4596.3 \\
\hline & $N_{2}$ & 2 & 6405 & 6302 \\
\hline & $N_{3}$ & 13 & 7466 & 6604 \\
\hline & $N_{4}$ & 1 & 7213 & 7124 \\
\hline
\end{tabular}

Table 5. Calibration results of crop parameters in CropSyst model for rice simulation in 2013

\begin{tabular}{c|c|c|c|c|c|c|c|c}
\hline Plant parameters & $\mathbf{E F}$ & $\mathbf{C}_{\mathbf{R M}}$ & $\mathbf{I O A}$ & $\mathbf{T}_{\text {test }}$ & $\mathbf{R M S E}_{\mathbf{n}}(\boldsymbol{\%})$ & $\mathbf{R M S E}$ & $\mathbf{R}^{\mathbf{2}}$ & $\begin{array}{c}\text { Number of } \\
\text { samples }\end{array}$ \\
\hline Biology Yield & 0.98 & 0.06 & 0.97 & 0.13 & 9 & 1264 & 0.77 & 12 \\
Grain Yield & 0.89 & -0.02 & 0.99 & 0.32 & 7 & 461 & 0.73 & 12 \\
LAI & 0.22 & 0.2 & 1 & 0.04 & 29 & 1 & 0.58 & 12 \\
\hline
\end{tabular}

Notes: $\operatorname{RMSE}_{\mathrm{n}}(\%)$ is the normalized root mean square error; $\mathrm{R}^{2}$ is the adjusted linear correlation coefficient between simulated and measured values; EF is the efficiency of model; IOA is the index of agreement; T test: tested the amounts with respect to the mean; CRM is the coefficient of residual mass 
Table 6. Validation results of crop parameters in the CropSyst model for rice simulation in 2014

\begin{tabular}{c|c|c|c|c|c|c|c|c}
\hline Plant parameters & EF & $\mathbf{C}_{\mathbf{R M}}$ & IOA & $\mathbf{T}_{\text {test }}$ & $\mathbf{R M S E}_{\mathbf{n}}(\boldsymbol{\%})$ & $\mathbf{R M S E}$ & $\mathbf{R}^{\mathbf{2}}$ & $\begin{array}{c}\text { Number of } \\
\text { samples }\end{array}$ \\
\hline Biological Yield & 0.80 & -0.04 & 0.96 & 0.27 & 10 & 1219 & 0.82 & 12 \\
Grain Yield & 0.98 & -0.14 & 0.98 & 0.03 & 15 & 847 & 0.84 & 12 \\
LAI & 0.38 & -0.7 & 1 & 0.02 & 68 & 82 & 0.82 & 12 \\
\hline
\end{tabular}

Notes: $\operatorname{RMSE}_{\mathrm{n}}(\%)$ is the normalized root mean square error; $\mathrm{R}^{2}$ is the adjusted linear correlation coefficient between simulated and measured values; EF is the efficiency of model; IOA is the index of agreement; $\mathrm{T}$ test: tested the amounts with respect to the mean; CRM is the coefficient of residual mass

The results of treatment evaluations showed that the average RMSE was equal to 847 $\mathrm{kg}$ per hectare, relative RMSE was $15 \%$, and CRM was -0.14, which, compared with $386 \mathrm{~kg}$ per hectare, $8 \%$, and 0.12 , was greater than the calibration phase, and indicates the closeness of the simulation amounts and validation values. For both calibration and validation phases, the amount of CRM that excluded the maximum LAI and dry material in the first year was negative, which showed that the amount in the simulation in most treatments was more than the observation amounts. In other words, in most treatments, the estimated amount of the model was more than the real amounts. Ouda et al. (2015), who reported The RMSE was $8 \%$ of the mean observed yield.

The EF under the calibration and evaluation conditions was also 0.89 and 0.87 , respectively. Based on the studies, simulation of this model under different levels of nitrogen was performed on corn plants, and the EF of the calibration and evaluation phases were 0.52 and 0.90 , respectively (Mohseni, 2008). Additionally, in other studies of the simulation of wheat plant yield by the CropSyst model, the value of the RMSE was equal to $0.21 \mathrm{Mg} / \mathrm{ha}$ and the value of the correlation factor was 0.72 (Sadras, 2002). Modeling efficiency (EF) were 0.82 and 0.75 for biomass and soil water content, respectively (Bellocchi et al., 2002; Tables 5 and 6 )

According to the research on the simulation of rice plant yield in North Italy, using the CropSyst model, the RMSE $\mathrm{n}_{\mathrm{n}}$ amplitude of dry material simulated measured for the calibration and validation year was $11 \%-29 \%$ and $10 \%-52 \%$, respectively, and the CRM amplitude of dry material simulated measured for calibration and validation years was $-0.03 \%$ to $0.17 \%$ and $-0.02 \%$ to $0.17 \%$, respectively (Confalonieri and Bocchi, 2005). Moreover, based on studies of the evaluation of the CropSyst model on the simulation of both the effects of water and nitrogen on wheat plants, the value of the RMSE for the simulation yield in the CropSyst model was $0.36 \mathrm{Mg} / \mathrm{ha}$. The value of the RMSE for the simulation of dry material in CropSyst was $1.27 \mathrm{Mg} / \mathrm{ha}$ (Saadati et al., 2012). The comparison of these results with the values gained in this research for rice plants showed that the CropSyst model could also simulate the rice yield well.

Results showed that the average RMSE yield biology under calibration and validation conditions were 1264 and $1219 \mathrm{~kg}$ per hectare respectively. The amounts of average $\mathrm{RMSE}_{\mathrm{n}}$ yield biology under calibration and validation conditions were also 9\% and $10 \%$, respectively. The EF that was obtained under calibration and evaluation conditions is also equal to 0.99 and 0.80 , respectively. For performance recognition of the CropSyst model in the simulation of dry material production and the yield of the reaction to the water and nitrogen, researchers studied the separate products in a season under experimental conditions with extensive preparations from dry to full irrigations 
and from low nitrogen existing in the soil to high level conditions. In these evaluations, the reported value of RMSE was 0.443 t/ha (Pala et al., 1996). Simulation results showed satisfactory application by suitable value of RMSE of biomass growth (0.58$3.52 \mathrm{t} \mathrm{ha}^{-1}$ ) and water content in the soil profile (20.9-50.6 mm) (Raza et al., 2014).

Results showed that the average RMSE under calibration and validation conditions were 1 and $0.80 \mathrm{~m}^{2}$ of leaf surface in each square meter at ground level. The values of $\mathrm{RMSE}_{\mathrm{n}}$ for the maximum LAI under calibration and validation conditions were 29 and 23, respectively. The results showed an acceptable accuracy of this model for simulation of the maximum LAI. The amounts of the measured parameters indicated that the medium simulation of this parameter, as well as the agriculture season by which this model can be used for planning of rice irrigation and nitrogen fertilizer management. The EF under calibration and evaluation conditions obtained were 0.12 and 0.32 , respectively.

Our observations showed that relative error of simulation yield in the calibration phase was $-15 \%$ to $15 \%$ and, in the evaluation phase, it was between $2 \%$ and $52 \%$. Additionally, the amount of biomass simulation relative error in the calibration phase was $-22 \%$ to $2 \%$ and in the evaluation phase, it was between $-10 \%$ and $27 \%$. Other research indicated that the amplitude amount of error for the growth simulation of the wheat plants between the simulation and observation yield in this plant was 2.7-37.2\% and, for dry material, it was between 2.2-30\% (Mohseni et al., 2008). Results showed that $\mathrm{R}^{2}$ for the calibration model data was 0.84 , which means that the model is suitable for grain yield simulation. Additionally, a relatively high $\mathrm{R}^{2}$ value means low dispersion of the data (Amiri and Rezaei, 2013a).

The amount of IOA (Willmott agreement index) was one of the most important indicators of the plants' assessment modeling. The IOA under calibration (first year) conditions for maximum LAI, grain yield, and dry material was 1, 0.99, and 0.97, respectively. Additionally, the IOA under evaluation conditions for maximum LAI, grain yield, and dry material was 1, 0.98, and 0.96, respectively. Results of the research by Zhang et al. (2011) show that IoA was in the excellent range (Zhang et al., 2011).

Tables 7-11 show the comparisons between the amounts of simulated and measured grain yield.

Table 7. Observed and simulated grain yields and relative error for rice in 2014

\begin{tabular}{c|c|c|c|c}
\hline \multicolumn{2}{c|}{ Treatment } & Relative error (\%) & $\begin{array}{c}\text { Simulation grain } \\
\text { yield (kg/ha) }\end{array}$ & $\begin{array}{c}\text { Observed grain } \\
\text { yield (kg/ha) }\end{array}$ \\
\hline \multirow{3}{*}{ Irrigation } & Nitrogen & 34 & 4867 & 3646.5 \\
$I_{1}$ & $N_{1}$ & 12 & 6622.6 & 5907.1 \\
& $N_{2}$ & 5 & 6614.6 & 6307 \\
& $N_{3}$ & 2 & 6705 & 6577 \\
& $N_{4}$ & 52 & 5276.3 & 3476.3 \\
$I_{2}$ & $N_{1}$ & 19 & 7225.1 & 6097 \\
& $N_{2}$ & 28 & 7266 & 5677 \\
& $N_{3}$ & 11 & 6966.8 & 6302 \\
$I_{3}$ & $N_{4}$ & 29 & 5030.1 & 3907.3 \\
& $N_{1}$ & 8 & 6470 & 5684.9 \\
& $N_{2}$ & 7 & 7040.4 & 6610 \\
& $N_{3}$ & 6 & 7140 & 6712 \\
\hline
\end{tabular}




$$
-2287 \text { - }
$$

Table 8. Observed and simulated LAI and relative error for rice in 2013

\begin{tabular}{c|c|c|c|c}
\hline \multicolumn{2}{c|}{ Treatment } & \multirow{2}{*}{ Relative error (\%) } & Simulation LAI & Observed LAI \\
\hline \multirow{4}{*}{ Irrigation } & Nitrogen & 89 & 3.19 & 2.28 \\
$I_{1}$ & $N_{1}$ & 9 & 4.31 & 4.13 \\
& $N_{2}$ & 5 & 4.25 & 4.6 \\
& $N_{3}$ & 12 & 4.87 & 4.82 \\
& $N_{4}$ & 39 & 3.55 & 1.73 \\
$I_{2}$ & $N_{1}$ & 33 & 4.69 & 2.83 \\
& $N_{2}$ & 20 & 4.69 & 2.62 \\
& $N_{3}$ & 36 & 4.19 & 4.9 \\
$I_{3}$ & $N_{4}$ & 4 & 2.4 & 1.68 \\
& $N_{1}$ & 26 & 4.52 & 3.59 \\
& $N_{2}$ & 31 & 5.3 & 3.8 \\
\hline
\end{tabular}

Table 9. Observed and simulated LAI and relative error for rice in 2014

\begin{tabular}{|c|c|c|c|c|}
\hline \multicolumn{2}{|c|}{ Treatment } & \multirow{2}{*}{ Relative error (\%) } & \multirow{2}{*}{ Simulation LAI } & \multirow{2}{*}{ Observed LAI } \\
\hline Irrigation & Nitrogen & & & \\
\hline \multirow{4}{*}{$I_{1}$} & $\overline{N_{l}}$ & 45 & 3.3 & 2.28 \\
\hline & $N_{2}$ & -3 & 4.01 & 4.13 \\
\hline & $N_{3}$ & -4 & 4.42 & 4.6 \\
\hline & $N_{4}$ & 2 & 4.9 & 4.82 \\
\hline \multirow{4}{*}{$I_{2}$} & $N_{l}$ & 106 & 3.65 & 1.73 \\
\hline & $N_{2}$ & 74 & 4.89 & 2.83 \\
\hline & $N_{3}$ & 79 & 4.89 & 2.62 \\
\hline & $N_{4}$ & 0 & 4.89 & 4.9 \\
\hline \multirow{4}{*}{$I_{3}$} & $N_{l}$ & 19 & 3.34 & 1.68 \\
\hline & $N_{2}$ & 24 & 4.4 & 3.59 \\
\hline & $N_{3}$ & 17 & 4.49 & 3.8 \\
\hline & $N_{4}$ & -8 & 5.32 & 5 \\
\hline
\end{tabular}

Table 10. Observed and simulated biomass and relative error for rice in 2013

\begin{tabular}{|c|c|c|c|c|}
\hline \multicolumn{2}{|c|}{ Treatment } & \multirow{2}{*}{ Relative error (\%) } & \multirow{2}{*}{$\begin{array}{c}\text { Simulation biomass } \\
(\mathrm{kg} / \mathrm{ha})\end{array}$} & \multirow{2}{*}{$\begin{array}{c}\text { Observed biomass } \\
\text { (kg/ha) }\end{array}$} \\
\hline Irrigation & Nitrogen & & & \\
\hline \multirow{4}{*}{$I_{I}$} & $N_{l}$ & -2 & 10,107 & 10,335 \\
\hline & $\mathrm{N}_{2}$ & -2 & 13,066 & 13,366 \\
\hline & $N_{3}$ & -15 & 13,051 & 15,397 \\
\hline & $N_{4}$ & -22 & 13,720 & 17,571 \\
\hline \multirow{4}{*}{$I_{2}$} & $N_{l}$ & 2 & 10,549 & 10,371 \\
\hline & $N_{2}$ & -1 & 14,326 & 14,532 \\
\hline & $N_{3}$ & 1 & 14,081 & 13,962 \\
\hline & $N_{4}$ & -7 & 14,100 & 15,100 \\
\hline
\end{tabular}




\begin{tabular}{l|l|l|l|l}
\hline & $N_{1}$ & -3 & 10,049 & 10,386 \\
\multirow{3}{*}{$\boldsymbol{I}_{3}$} & $N_{2}$ & -7 & 12,811 & 13,772 \\
& $N_{3}$ & -9 & 14,221 & 15,684 \\
& $N_{4}$ & -6 & 14,062 & 14,985 \\
\hline
\end{tabular}

Table 11. Observed and simulated biomass and relative error for rice in 2014

\begin{tabular}{|c|c|c|c|c|}
\hline \multicolumn{2}{|c|}{ Treatment } & \multirow{2}{*}{$\begin{array}{c}\text { Relative error } \\
(\%)\end{array}$} & \multirow{2}{*}{$\begin{array}{c}\text { Simulation biomass } \\
(\mathrm{kg} / \mathrm{ha})\end{array}$} & \multirow{2}{*}{$\begin{array}{c}\text { Observed biomass } \\
\text { (kg/ha) }\end{array}$} \\
\hline Irrigation & Nitrogen & & & \\
\hline \multirow{4}{*}{$I_{I}$} & $N_{l}$ & 17 & 9735 & 10,335 \\
\hline & $N_{2}$ & 18 & 13,244 & 13,366 \\
\hline & $N_{3}$ & -5 & 13,228 & 15,397 \\
\hline & $N_{4}$ & 0 & 13,688 & 17,571 \\
\hline \multirow{4}{*}{$I_{2}$} & $N_{l}$ & 15 & 10,553 & 10,371 \\
\hline & $N_{2}$ & 7 & 14,451 & 14,532 \\
\hline & $N_{3}$ & -3 & 14,532 & 13,962 \\
\hline & $N_{4}$ & -4 & 14,232 & 15,100 \\
\hline \multirow{4}{*}{$I_{3}$} & $N_{l}$ & 26 & 9661 & 10,386 \\
\hline & $N_{2}$ & 27 & 12,940 & 13,772 \\
\hline & $N_{3}$ & -4 & 13,241 & 15,684 \\
\hline & $N_{4}$ & -10 & 13,451 & 14,985 \\
\hline
\end{tabular}

Results showed a change from flood to intermittent irrigation, the real grain yield decreased, and the increase of nitrogen consumption led to the grain yield increasing. The model also showed a decrease and an increase in simulated grain yield pretty well. The minimum amount of grain yield was under the condition of the non-use of nitrogen fertilizer, and the maximum yield was under the nitrogen treatment condition of $120 \mathrm{~kg}$ $\mathrm{N}$ per hectare, with intermittent irrigation was every 5-8 days.

It is worth noting that low irrigation is also effective in this matter. In 5-day irrigation management, the model could not simulate the yield well because of incompetent ability to estimate grain yield. The existence of some weather parameters, such as wind speed and carbon dioxide changes in the farm, which were not present in the model (the model anticipates grain yield according to other climate parameters) might also be another reason for the decrease in foresight accuracy by the model (Honar et al., 2010).

In testate fertilizer amounts, the error percent of the model was higher, but it will be decreased by increasing the fertilizer amounts so that after forth fertilizer application the error will be erased completely. Changes in the amount of simulated grain yield by the CropSyst model for the first and second year are shown in Figure 2. The minimum amount of grain yield was under the condition of the non-use of nitrogen fertilizer, and maximum yield was under nitrogen treatment condition of $120 \mathrm{~kg}$ nitrogen per hectare and intermittent irrigation was every eight days. The results showed that the gain yield would increase by increasing the nitrogen consumption. The model also showed fluctuations in simulated grain yield rather well. The amount of grain yield will increase by adding more nitrogen via irrigation management, but in higher levels of nitrogen (150 and $120 \mathrm{~kg} \mathrm{ha}^{-1}$ ) a slight increase will be shown. According to other indices to 
assess irrigation regimes and fertilizer levels, the most suitable treatments regarding environmental aspect were 5-day irrigation regime and $45 \mathrm{~kg} \mathrm{~N}^{-1}$ (Zare et al., 2014).

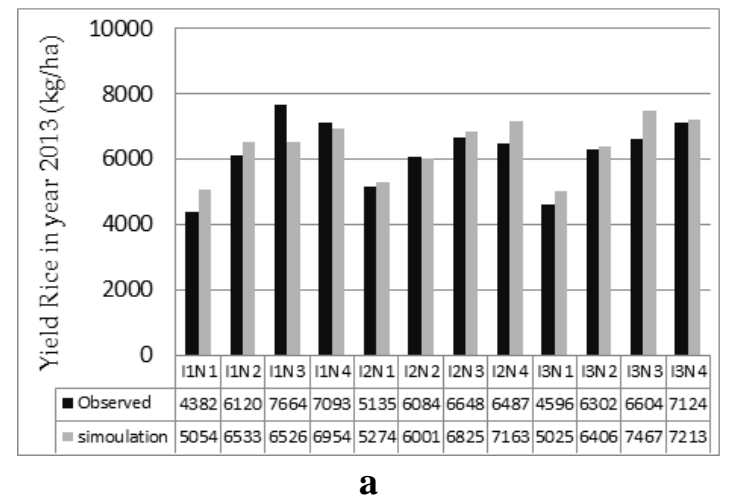

$\mathbf{a}$

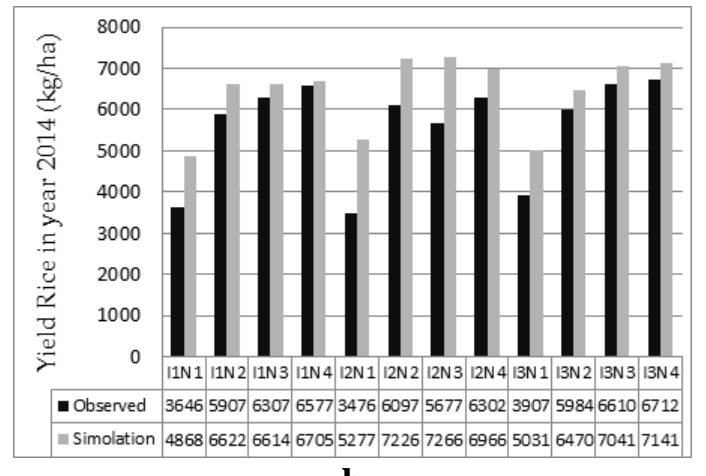

b

Figure 2. Observed and simulated grain yields for rice in 2013 and 2014. Irrigation. ( II = continuously flooded, $I 2=5$ per day, $I 3=8$ per day) and $N$ fertilizer $(N 1=0, N 2=90$, $N 3=120, N 4=150(\mathrm{~kg} / \mathrm{ha}))$

On the other hand, the grain yield will decline under flood irrigation conditions. Additionally, by changing the irrigation model from flood to intermittent treatments of every 5-8 days, simulated grain yield will show a slight increase; this indicates that the amount of nitrogen consumption is more than the nutritional needs of the spring type of rice in this research. Changing of the irrigation from flood to intermittent will reduce hydrostatic pressure at the ground level, which causes a reduction of water loss through leakage and deep percolation (Bouman et al., 2007).

Results of the research showed that the change in flood irrigation management reduced deep losses. Therefore, investigation of results about the amount of leakage and deep percolation in the period of the research showed the minimum and maximum water loss through deep percolation as 117 and $221 \mathrm{~mm}$, respectively, under flood and non-flood management (Amiri and Rezaei, 2013a). Results also indicated that changing from flood to non-flood irrigation reduced irrigation water, which was consistent in other studies (Pirmoradian et al., 2004; Amiri and Rezaei, 2013a).

Other studies showed that changing the irrigation method from flood to non-flood will result in saving irrigation water. Due to the increasing competition for water, watersaving technologies, such as alternate wetting, drying, and aerobic rice are being developed to reduce water consumption while maintaining a high yield. The components of the water balance of these systems need to be disentangled to extrapolate water savings from the field scale to the irrigation system scale (Bouman et al., 2007). As shown in this study, irrigation and $\mathrm{N}$ fertilizer management improved the efficiency of water consumption and, thus, reduced the impact of water shortages. The results of this study provided a basic information base for making irrigation and $\mathrm{N}$ management decisions in the study area.

\section{Water productivity estimation}

The amount of water productivity was calculated based on the sum of water and rainfall, as shown in Table 12. The results show that the change in flood irrigation management increased water productivity. The model also showed the simulated 
decrease and increase rather well. Additionally, results from the treatments of $\mathrm{I}_{3} \mathrm{~N}_{3}$ and $\mathrm{I}_{3} \mathrm{~N}_{4}$ in both models showed the greatest amount of water productivity was in the first and second years. This result suggests that the mechanism of the plant's production performance, despite the reduction in available water to the surface, has been successful. Furthermore, the value of the evaporation results in the CropSyst model showed that, in irrigation flood management, up to $39 \%$ of evapotranspiration occurs. While the value of intermittent irrigation management of five and eight days, respectively, was $35 \%$ and $32 \%$. The amount of water productivity was calculated based on the sum of water and rainfall, with greater reliance on management practices, especially irrigation methods. The results Jalotal et al. (2006) suggest that water productivity in rice can be enhanced mainly by adjusting the transplanting date. The enhanced water productivity in delayed transplanted paddy was due to reduction in ET while the yield remained unaffected (Jalotal et al., 2006). Results of the research by Umair et al. (2017) E was 30\% of total ETa and results closely matched the observed data collected during the MLM and isotopes approach (Umair et al., 2017).

Table 12. Simulated grain yield and water productivity amounts via the CropSyst model

\begin{tabular}{|c|c|c|c|c|c|c|c|c|}
\hline Year & Irrigation & Nitrogen & $\mathbf{P}(\mathbf{m m})$ & I (mm) & $\mathbf{E}(\mathbf{m m})$ & ET (mm) & GY $(\mathrm{kg} / \mathbf{h})$ & $W P$ \\
\hline \multirow{12}{*}{2013} & \multirow{4}{*}{$I_{I}$} & $N_{l}$ & 79 & 744 & 330 & 537 & $5053 / 8$ & 0.61 \\
\hline & & $N_{2}$ & 79 & 724 & 350 & 586 & $6533 / 6$ & 0.81 \\
\hline & & $N_{3}$ & 79 & 712 & 347 & 550 & $6525 / 6$ & 0.83 \\
\hline & & $N_{4}$ & 79 & 732 & 363 & 544 & $6953 / 6$ & 0.86 \\
\hline & \multirow{4}{*}{$\mathrm{I}_{2}$} & $\mathrm{~N}_{1}$ & 79 & 701 & 340 & 487 & $5273 / 3$ & 0.68 \\
\hline & & $\mathrm{N}_{2}$ & 79 & 703 & 329 & 495 & 6001 & 0.77 \\
\hline & & $\mathrm{N}_{3}$ & 79 & 701 & 382 & 498 & $6825 / 9$ & 0.88 \\
\hline & & $N_{4}$ & 79 & 707 & 385 & 464 & $7163 / 1$ & 0.91 \\
\hline & \multirow{4}{*}{$I_{3}$} & $N_{l}$ & 79 & 469 & 270 & 429 & $5024 / 1$ & 0.92 \\
\hline & & $\mathrm{N}_{2}$ & 79 & 459 & 273 & 444 & 6405 & 1.19 \\
\hline & & $N_{3}$ & 79 & 461 & 297 & 431 & $7466 / 4$ & 1.38 \\
\hline & & $N_{4}$ & 79 & 429 & 331 & 431 & 7213 & 1.42 \\
\hline \multirow{12}{*}{2014} & \multirow{4}{*}{$I_{1}$} & $N_{l}$ & 59 & 804 & 330 & 533 & $4867 / 8$ & 0.56 \\
\hline & & $\mathrm{N}_{2}$ & 59 & 801 & 407 & 586 & $6622 / 6$ & 0.77 \\
\hline & & $N_{3}$ & 59 & 789 & 347 & 550 & $6614 / 6$ & 0.78 \\
\hline & & $N_{4}$ & 59 & 795 & 360 & 544 & $6705 / 6$ & 0.79 \\
\hline & \multirow{4}{*}{$\mathrm{I}_{2}$} & $\mathrm{~N}_{1}$ & 59 & 726 & 319 & 550 & $5276 / 3$ & 0.67 \\
\hline & & $\mathrm{N}_{2}$ & 59 & 741 & 362 & 551 & $7225 / 1$ & 0.9 \\
\hline & & $\mathrm{N}_{3}$ & 59 & 746 & 382 & 493 & $7266 / 9$ & 0.9 \\
\hline & & $N_{4}$ & 59 & 746 & 360 & 502 & $6966 / 18$ & 0.87 \\
\hline & \multirow{4}{*}{$I_{3}$} & $N_{l}$ & 59 & 419 & 271 & 518 & $5030 / 1$ & 1.05 \\
\hline & & $N_{2}$ & 59 & 459 & 318 & 436 & 6470 & 1.2 \\
\hline & & $N_{3}$ & 59 & 496 & 251 & 439 & $7040 / 4$ & 1.27 \\
\hline & & $N_{4}$ & 59 & 466 & 330 & 429 & 7140 & 1.3 \\
\hline
\end{tabular}

$\mathrm{I} 1=$ Continuously flooded, $\mathrm{I} 2=5$ per day, $\mathrm{I} 3=8$ per day and $\mathrm{N}$ fertilizer $\mathrm{N} 1=0, \mathrm{~N} 2=90, \mathrm{~N} 3=120$, $\mathrm{N} 4=150(\mathrm{Kg} / \mathrm{ha})$

$P=$ Precipitation, $I=$ Irrigation, $E=$ Evaporation, $E T=$ Evapotranspiration, $G Y=$ Grain Yield, $W P=$ Water productivity 
Results of the research by Amiri and Rezaei (2013a) show that the change in flood irrigation management reduces deep losses (Amiri and Rezaei, 2013a). So that investigation of results about the amount of leakage and deep percolation in a period of the research show the minimum and maximum of water dissipation through deep percolation as 117 and $221 \mathrm{~mm}$, respectively, in flood and non-flood conditions. Results of that study also indicates that changing from flood to non-flood irrigation reduces irrigation water consumption, which is consistent with the research of Pirmoradian et al. (2004). They showed that changing irrigation methods from flood to non-flood will result in saving irrigation water (Pirmoradian et al., 2004).

Irrigation and $\mathrm{N}$ fertilizer management, as shown in this study, improves the efficiency of water use and, thus, reduces the impact of limited water. The results of the study provided an information base for making irrigation and $\mathrm{N}$ management decisions in the study area. These results suggest that due to the good simulation models and maximum data consistency that the CropSyst model can be used to support the management and optimization of water and nitrogen fertilizer to cultivate rice.

\section{Conclusions}

The CropSyst model was sufficiently accurate in the simulation of yield underwatersaving and crop density conditions for our study site. The results of this study clearly indicate that the CropSyst model can be used with a high degree of accuracy for yield simulation and were similar to those of other researchers (Asadi et al., 2003; Bouman et al., 2007; Amiri and Rezaei, 2013a; Umair et al., 2017). The CropSyst model could also simulate the rice yield rather well. An agreement index (IOA) was also used to evaluate the model. Given the negligible difference between observed and simulated value performance, it can be concluded that this model might be useful as a simulated model of the effect of water and nitrogen management which can be used in yield estimates. The results of this study showed that the model generally predicted grain yield and final biomass fairly satisfactorily across a range of datasets covering levels of irrigation and $\mathrm{N}$ conditions within two years in Northern Iran.

Thus, the most optimal conditions to offer to farmers was under nitrogen treatment condition of $120 \mathrm{~kg}$ nitrogen per hectare and intermittent irrigation was every eight days.

In the current study, the CropSyst crop simulation model was calibrated, validated, and used as a tool to provide estimates of water productivity of rice under a range of $\mathrm{N}$ fertilizer and water regimes in a humid region of Iran. The simplicity of the model in its required minimum input data, which are readily available or can be easily collected, makes it user friendly. The authors suggest that for better validation of models using other models and other concentration Nitrogen and Irrigation Management in Other areas suitable for rice cultivation.

Aknowledgments. The authors are grateful to the Rasht Rice Research Institute, for providing resources and for providing facilities.

Author contributions. Farzad Paknejad, Ebrahim Amiri, Bahram Mirshekari, Mojtaba Mirakhori designed and performed the research. Ebrahim Amiri analyzed the data, discussed the results and wrote the paper. Bernd Honermeier, commented and edited the manuscript.

Conflicts of interest. The author claimed no conflict of interest. 


\section{REFERENCES}

[1] Amiri, E., Rezaei, M. (2013a): Evaluation of water balance components and water productivity of rice under interval irrigation and nitrogen fertilizer conditions. - Iranian Journal of Irrigation and Drainage 6(4): 306-315.

[2] Amiri, E., Rezaei, M. (2013b): Calibration and evaluation of CERES rice model under different nitrogen and water management options in semi mediterranean climate condition. - Communications in Soil Science and Plant Analysis 44: 1814-1830.

[3] Araya, A., Habtu, S., Hadgu, K. M., Kebede, A., Dejene, T. (2010): Test of AquaCrop model in simulating biomass and yield of water eficient and irrigated barley (Hordeum vulgare). - Agric. Water Manage 97: 1838-1846.

[4] Asadi, Rezaei, V., Motamed, K. (2003): A simple solution to cope with droughts in the Caspian fields. - Iranian Journal of Dryland Drought 4(1): 91-87.

[5] Bellocchi, G., Silvestri, N., Mazzoncini, M., Menini, S. (2002): Using the CropSyst model in continuous rainfed maize (Zea mais L.) under alternative management options. - Italian Journal of Agronomy 6(1): 43-56.

[6] Bouman, B., Feng, L., Tuonga, T. P., Lu, G., Wang, H., Feng, Y. (2007): Exploring options to grow rice using less water in northern China using a modelling approach II. Quantifying yield, water balance components and water productivity. - Agricultural Water Management 88: 23-33.

[7] Confalonieri., R., Bocchi, S. (2005): Evaluation of CropSyst for simulation the yield of flooded rice in northern Italy. - Europe. J. Agronomy 23: 315-326.

[8] Confalonieri, R., Acutis, M., Bellocchi, G., Cerrani, I., Tarantola, S., Donatelli, M., Genovese, G. (2006): Exploratory sensitivity analysis of CropSyst WARM and WOFOST: a case-study with rice biomass simulations. - Ital. J. Agrometeorol 11: 17-25.

[9] Confalonieri, R., Acutis, M., Bellocchi, G., Donatelli, M. (2009): Multi-metric evaluation of the models WARM, CropSyst, and WOFOST for rice. - Ecological Modelling 220: 1395-1410.

[10] Diaz-Ambrona, C. G. H., O’Leary, G. J., O’Connell, M. G., Connor, D. J. (2001): Application of CropSyst to a New Location and Crops: Advantages and Limitations. Proceedings of the Second International Symposium on Modelling Cropping Systems, pp. 127-128. European Society for Agronomy, Division Agroclimatology and Agronomic Modelling, Florence, Italy.

[11] Eitzinger, J., Stastna, M., Zalud, Z., Dubrousky, M. (2004): A simulation study of the effect of soil water balance and water stress on winter wheat production under different climate change scenarios. - Agric. Water. Manage. 61: 195-217.

[12] Fila, G, Bellocchi, G., Acutis, M, Donatelli, M. (2003): Irene: a software to evaluate model performance. - Eur J Agron 18: 369-372.

[13] Honar, T., Sabet, T., Sarvestani, A., Kamkar, A. A., Shams, S. (2010): Calibration model CropSyst to estimate crop yield and growth seed oil. - Iranian Journal of Sciences Water and Soil 25(3): 593_605.

[14] Jalotal, S. K., Singh, G. B., Ray, S. S. (2006): Performance of Cropsyst model in ricewheat cropping system. - Jour. Agric. Physics 6(1): 7-13.

[15] Keating, B. A., Carberry, P. S., Hammer, G. L., Probert, M. E., Robertson, M. J., Holzworth, D., Huth, N. I., Hargreaves, J. N. G., Meinke, H., Hochman, Z., McLean, G., Verburg, K., Snow, V., Dimes, J. P., Silburn, M., Wang, E., Brown, S., Bristow, K. L., Asseng, S., Chapman, S., McCown, R. L., Freebairn, D. M., Smith, C. J. (2003): An overview of APSIM, a model designed for farming systems simulation. - Eur. J. Agron. 18: 267-288.

[16] Khov, S, Vote, C., Hornbuckle, J., Inthavong, I., Oeurng, C., Sengxua, P., Sihathep, V., Song, L., Eberbach, P. (2017): Calibration and validation of AquaCrop for irrigated peanut (Arachis hypogaea) in lowland rice systems of southern Laos. - Paper presented at 
the 22nd International Congress on Modelling and Simulation, Hobart, Tasmania, Australia, 3 to 8 December.

[17] Kumar, R., Sarawgi, A. K., Ramos, C., Amarante, S. T., Ismail, A. M., Wade, L. J. (2006): Partitioning of dry matter during drought stress in rain fed lowland rice. - Field Crops Res. 98: 1-11.

[18] Li, Y., Barker, R. (2004): Increasing water productivity for paddy irrigation in China. Paddy Water Environ. 2: 187-193.

[19] Mohseni, M., Montazer, A., Rahimi, A. (2008): The evaluation model of plant CropSyst in the simulation, the combined effect of water and nitrogen on yield and water productivity of wheat. - Iranian Journal of Sciences Irrigation \& Drainage Iran 3(1): 113125 .

[20] Ouda, S. A., Noreldin, T., Mounzer, O. H., Abdelhamid, M. T. (2015): CropSyst model for wheat irrigation water management with fresh and poor quality water. - Journal of Water and Land Development 27(X-XII): 41-50.

[21] Pala, M., Stöckle, C. O., Harris, H. C. (1996): Simulation of durum wheat (Triticum turgidum ssp. durum) growth under different water and nitrogen regimes in a Mediterranean environment using CropSyst. - Agric. Syst. 51: 147-163.

[22] Pirmoradian, N., Sepaskah, A. R., Maftoun, M. (2004): Effects of water-saving irrigation and nitrogen fertilization on yield and yield components of rice (Oryza sativa L.). - Plant Production Science 7(3): 337-346.

[23] Raza, A., Moghaddam, A., Friedel, K. (2014): Evaluation of CropSyst for studying the effect of mulching with lucerne (Medicago sativa L.) in Austria. - Journal of Plant Interactions 9(1): 592-598.

[24] Razavipour, T., Y. M., Kavosi, M. (2007): The effects of water stress in the different growing stage on rice yield. - Paper presented at the 6th National Conference on Soil Science, Tehran, Iran, pp. 613-614.

[25] Saadati, Z., Pirmoradian, N., Rezaei, M. (2012): Assessment of CropSyst model in yield simulating of two rice varieties, under different irrigation regimes. Dissertation. - Iranian Journal of Sciences Water and Soil 64(17): 1-12.

[26] Sadras, V. O. (2002): The interaction between rainfall and nitrogen fertilization of wheat in environments prone to terminal drought: economic and environmental risk analysis. Field Crops Res. 77: 201-215.

[27] Singh, A. K., Tripathy, R., Chopra, U. K. (2008): Evaluation of CERES-Wheat and CropSyst models for water-nitrogen interactions in wheat crop. - Agricultural Water Management 95: 776-786.

[28] Stöckle, C. O., Donatelli, M., Nelson, R. (2003): CropSyst a cropping systems simulation model. - European Journal of Agronomy 18(3): 289-307.

[29] Umair, M., Shen, Y., Qi, Y., Zhang, Y., Ahmad, A., Pei, H., Liu, M. (2017): Evaluation of the Cropsyst model during wheat-maize rotations of the North China Plain for identifiying soil evaporation losses. - Frontiers in Plant Sience 8: 1-14.

[30] Zare, N., Khaledian, M. R., Pirmoradian, N., Rezaei, M. (2014): Simulation of rice yield under different irrigation and nitrogen application managements by CropSyst model. Acta Agriculturae Slovenica 103(2): 181-190.

[31] Zhang, Y., Shen, Y., Sun, H., Gates, J. B. (2011): Evapotranspiration and its partitioning in an irrigated winter wheat field: a combined isotopic and micrometeorologic approach. - J. Hydrol. 408: 203-211. 